\title{
THE HARDWARE IMPLEMENTATION AND SIGNAL CONTROL OF SANDA ELECTRONIC PROTECTION DEVICES
}

\author{
Daoye Lu*1, Xingwei Si², Xia Feng ${ }^{3}$ \\ ${ }^{1}$ College of Competitive Sports and Physical Education, Rizhao \\ Campus of Shandong Sport University, Shandong Road (East), \\ Donggang District, Rizhao City, Shandong, China \\ ${ }^{2,3}$ He'nan Normal University Physical culture institute, Xinxiang, Henan, 453007, China \\ Email:wmgcuo@163.com
}

\begin{abstract}
The application of electronic protection devices promotes the development of Taekwondo competition and has been an important factor influencing the competition performance of athletes. Also, it can help to promote Sanda, a sports item with a history longer than Taekwondo, to all over the world; however, there are few studies concerning Sanda electronic protection devices. Hence based on the study on the Taekwondo electronic protection devices and according to the competition rules of Sanda, this study proposed a design scheme for the Sanda electronic protection device. Firstly, the hardware of the electronic protection device was designed to implement the functions; then the signal control of the electronic protection device was investigated and the functions of signal collection, transmission and processing were designed; finally, experimental simulation and analysis were performed on the above designed part. The simulation results demonstrated that, the Sanda electronic protection device designed in this study was feasible and can promote the research progress of Sanda electronic protection devices.
\end{abstract}

Keywords: Sanda electronic protection device; signal control; hardware; optical fiber sensor; circuit; handle.

\section{Introduction}

Electronic protection device equipped with electron device, sensors [1-3] and other electronic devices is a new type of electronic device developed in recent years. It is well known by people because of the application of its scoring system in Taekwondo competition. Its application eliminates unfair judgment and also promotes the objectivity, fairness, ornamental value and intensity of competitions.

Sanda $[4,5]$ originating from Chinese civilization with a long history is not only a kind of wrestling form, but also a sports event with Chinese national characteristics. Moreover, it was approved as a formal competition event by the National Sports Commission in 1989 and gradually becomes normalized and internationalized. Therefore, it is quite necessary to study and design Sanda electronic devices. However, because of the complicated rules and multiple judgment ways of Sanda competition, it is seldom concerned domestically and internationally except professional athletes and referees and its promotion and popularization is still difficult.

Currently, there are few studies concerning Sanda electronic devices in China, professional device entity has not been produced yet, and the present Sanda protection electronic devices only include the most basic ones, such as boxing gloves, head protection devices and body protection devices [6]. To make Sanda intelligentialized and high-speed, internationalize Sanda, and inherit and promote Chinese Wushu, this study proposed a Sanda electronic protection device system and designed the hardware equipment and signal control of the device $[7,8]$, aiming to implement the system function of the electronic protection device, protect Sanda athletes better, realize the professionalization and justification of Sanda competition, and spread Sanda over the world.

\section{Hardware system of Sanda electronic devices}

\subsection{The design of sensor}

In this study, a fiber optic microbend sensor with micro-bending property was designed in this study. The fiber optic microbend sensor composed of a microbend modulator [9] and optical fibers conformed to the service conditions of Sanda electronic protection devices. Its system structure is shown in figure 1. 


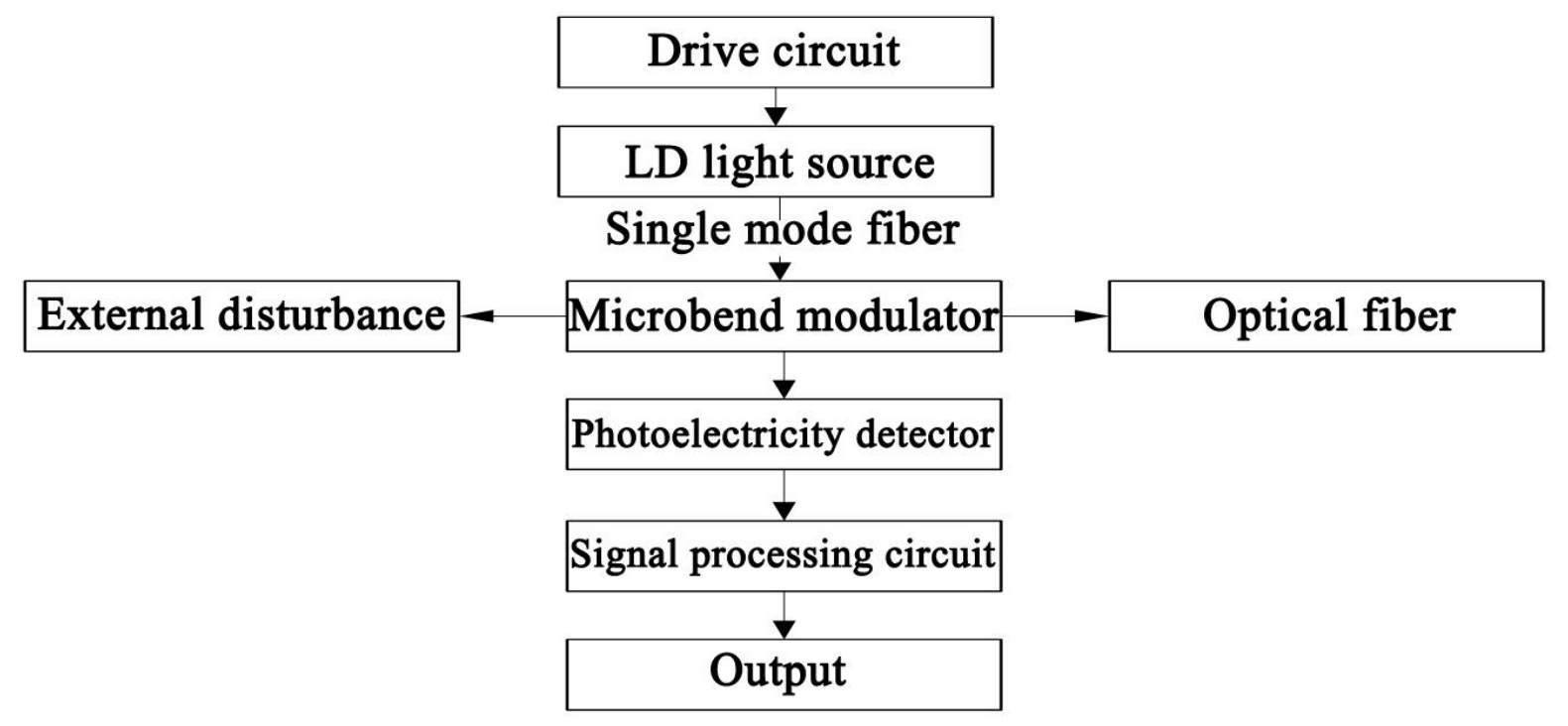

Figure 1: The system structure of optical fiber sensor

As shown in figure 1, when the driving circuit operated under the effect of voltage signal, the light source was driven to give out light and the light was transmitted through the single mode fiber in the microbend modulator.

When the athlete stroke the microbend modulator, the optical fibre was bent, leading to the changes of light intensity, the photoelectric detector transformed optical signals to electric signals according to the changes of optical intensity, and they were output after signal processing. The sensor designed in this study evaluated Sanda movements through detecting their strength by outputting voltage values under external hitting strength. Suppose that the external disturbance variable undertaken by the optical fibers as $\Delta q$, the deformation amount of optical fiber as $\Delta x$, and the variation of bending loss as $\Delta P$; then formula (1) was obtained (D: constant correlated to external disturbance $\Delta q ; \Delta x=\mathrm{D} \Delta q$ ). If $\Delta F$ was the force exerted on the optical fibers, then formula (2) was obtained (Kf: mechanical constant of bending amount of the optical fibers; As: the sectional area of optical fibers, $\mathrm{Y}_{\mathrm{s}}$ : Young modulus; $\mathrm{l}_{\mathrm{s}}$ : the length of modulator).

$$
\begin{aligned}
& \Delta P=D \frac{\Delta P}{\Delta x} \Delta q \\
& \Delta P=\frac{\Delta P}{\Delta x} \Delta F\left(K_{f}+\frac{A_{s} Y_{s}}{l_{s}}\right)^{-1}
\end{aligned}
$$

It could be noticed from the above formula that, the optical transmission efficiency changed when the external hitting strength changed; the hitting strength could be directly known based on the output voltage signal of the optical detector.

Ultralumin featured by large bearing capacity, good elasticity and long service life was selected as the material for the microbend modulator. The finished product was obtained after cutting process using special techniques. The structure of the microbend modulator is shown in figure 2 . The microbend sensor used in the experiment is shown in figure 3.

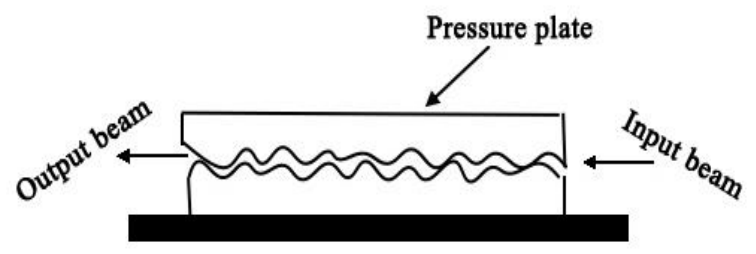

Figure 2: The structure of the microbend modulator

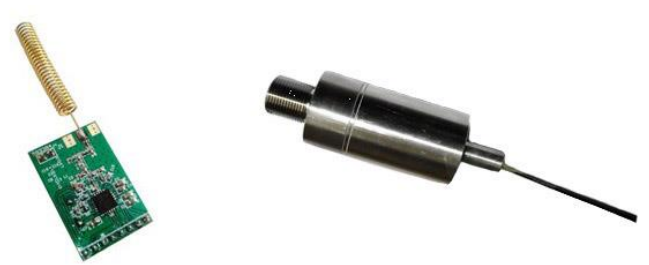

311/433M wireless module Microbend optical fibre sensor

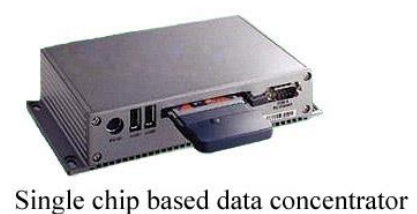

Figure 3: Different parts of the microbend sensor

\subsection{System circuit design}

The circuit design involves two aspects, i.e., charge amplifier circuit and core processor circuit.

Firstly, charge amplifier circuit was designed in the sensors and system processing devices. 
The variation of trace charge and voltage was amplified into large voltage output which could be easily identified by the system. The design principles are shown in figure 4 . The output value depended on the size of the pressure charge coefficient and capacitance. Output frequency was obtained based on the proportion of the capacitance [10] and resistance of resistance-capacitance circuit.

When the frequency was larger than $1 / 2 \pi \times \mathrm{R} \times$ $C$, the output voltage of the amplifier was $V_{P}=\frac{1}{C} \times d \times F_{P}$

$\left(F_{\mathrm{p}}\right.$ : the vertical force exerted on the surface of the sensor). Secondly, MSP430f149 single chip with the properties of high-speed processing efficiency and multiple communication modes was selected in the design of core processor circuit.

Through circuit design and resource allocation, the whole circuit was controlled at a relatively low level through printed circuit board customization after corresponding resource ports were set apart. In this way, the power source and voltage detection circuit was integrated to indicate power source. Finally, the design of the whole circuit system was implemented.

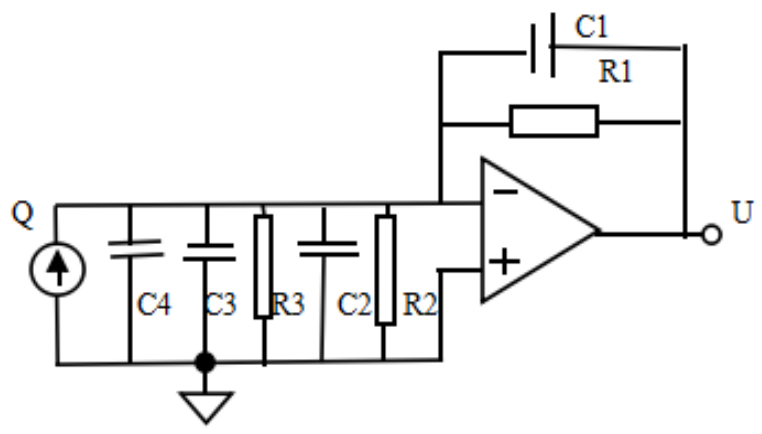

Figure 4: The schematic diagram of charge amplifier circuit

\subsection{The design of referee handle}

The design of referee handle involved chief referee handle and assistant referee handle. Two options, i.e., $A$ and $B$, were set to distinguish scores. The score ranged from $1 \sim 3$ points, and the referee could press the corresponding button for one, two or three times. To ensure the security and stability of the system, the power supply for the handles was the same. Wireless transmission was used in the design of the chief referee handle. Signals were transmitted to a data concentrator. Moreover, options such as advice, warning, start, stop and finish were also set to totally control whole competition. The following is a conceptual drawing of the chief referee handle. The scoring could be completed by only one hand of the main referee. The other hand could be used for processing emergency.

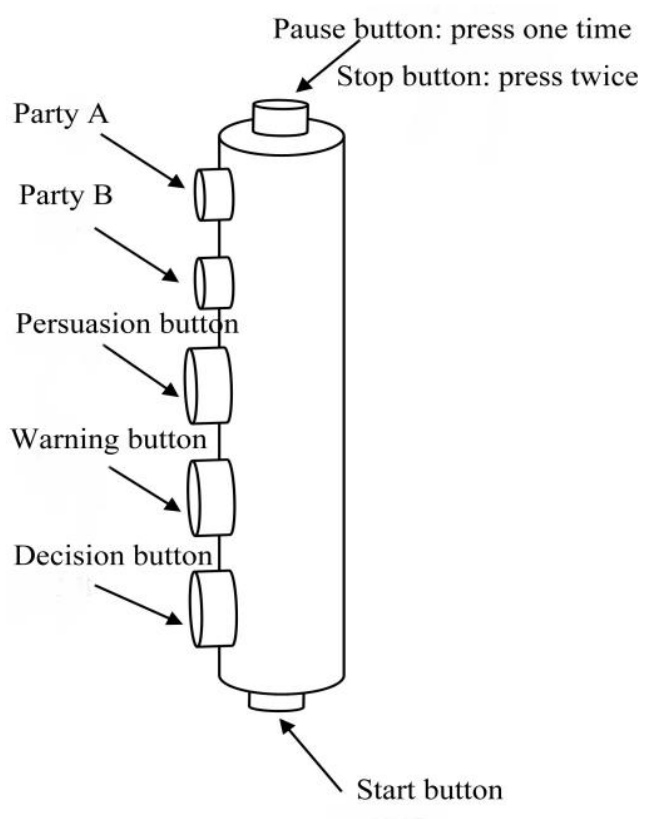

Figure 5: The conceptual drawing of the chief referee handle

\section{Signal control of the Sanda electronic protection device}

The signal control functions of the Sanda electronic protection device system designed in this study mainly included the acquisition, transmission and processing of data signals. Signals were collected by the optical fiber sensor, transmitted by the data wireless transmission module, and processed by the data concentrator. As the design of the optical fiber sensor had been completed, only the design of wireless transmission module and data concentrator was done in the following.

\subsection{Data signal transmission of the electronic protection devices}

According to the rules of Sanda competition, both players can freely move in the competition field. Therefore, wireless data transmission [11, 12] is necessary to implement data transmission better. Data were collected using the sensors and transmitted by the wireless transmission module. Wireless modules that circulate in market currently mainly include $311 / 433 \mathrm{M}$ wireless module and $2.4 \mathrm{G}$ wireless module. $311 / 433 \mathrm{M}$ wireless transmission module which adopts amplitude modulation (AM), surface acoustic wave (SAW) resonator frequency stabilization and amplitude shift keying modulation has quite stable frequency and can effectively reduce power consumption and achieve long-distance data transmission. $311 / 433 \mathrm{M}$ used in the experiment is shown in figure 3. 
The location change of athletes and audience will disturb wireless signals; in addition, it can be known from the formula about loss in the signal transmission in air, i.e.,

Los $=32.44+20 \lg d+20 \lg f$ (Los: transmission loss; d: distance; $\mathrm{f}$ : frequency) that, when transmission distance is fixed, the higher the frequency is, the larger the transmission loss is; when transmission loss is fixed, the higher the frequency is the shorter the transmission distance is. Thus the typical HAC-UM from 433M wireless module which can satisfy the design requirement of Sanda electronic protection devices was selected as the data transmission module in this study.
The main technical indicators of the module are shown in table 1.

The application of micro-power transmission, industrial scientific medical frequency point, Gaussian frequency-shift keying based modulation mode and high-efficient forward error correcting information channel coding technique effectively improved the anti-disturbance function of data and reduced data error rate. Low power consumption was also considered in the design of the module, which could reduce power consumption and ensure the stability of data transmission during the implementation of high-efficient data transmission.

Table 1. Technical indicators of HAC-UM

\begin{tabular}{|l|l|l|l|}
\hline $\begin{array}{l}\text { Modulation } \\
\text { mode }\end{array}$ & GFSK/FSK & $\begin{array}{l}\text { Operating } \\
\text { temperature }\end{array}$ & $\begin{array}{l}-20^{\circ} \mathrm{C} \sim 70^{\circ} \mathrm{C} \text { (ordinary) } \\
-35^{\circ} \mathrm{C} \sim 80^{\circ} \mathrm{C} \text { (industrial grade) }\end{array}$ \\
\hline $\begin{array}{l}\text { Working } \\
\text { frequency }\end{array}$ & $429.00 \sim 434.90 \mathrm{MHz}$ & Power source & $+3.3 \sim 5.5 \mathrm{VDC}$ \\
\hline $\begin{array}{l}\text { Emission } \\
\text { power }\end{array}$ & $10 \mathrm{dBm}$ & Size & $47 \mathrm{~mm} \times 26 \mathrm{~mm} \times 10 \mathrm{~mm}$ \\
\hline $\begin{array}{l}\text { Data interface } \\
\text { format }\end{array}$ & $8 \mathrm{E} 1 / 8 \mathrm{~N} 1$ & $\begin{array}{l}\text { Emission } \\
\text { current }\end{array}$ & $\leq 42 \mathrm{~mA}$ \\
\hline $\begin{array}{l}\text { Receiving } \\
\text { sensitivity }\end{array}$ & $\begin{array}{l}-105 \sim-118 \mathrm{dBm} \\
-112 \mathrm{dBm} @ 9600 \mathrm{bps}(1 \% \mathrm{BER})\end{array}$ & $\begin{array}{l}\text { Receiving } \\
\text { current }\end{array}$ & $\leq 32 \mathrm{~mA}$ \\
\hline $\begin{array}{l}\text { Channel } \\
\text { bandwidth }\end{array}$ & $\begin{array}{l}12.5 \mathrm{~K} @ 1200 \mathrm{BPS} \\
100 \mathrm{~K} @ 9600 \mathrm{BPS}\end{array}$ & $\begin{array}{l}\text { Dormant } \\
\text { current }\end{array}$ & $\leq 5 \mu \mathrm{A}$ \\
\hline Interface rate & $\begin{array}{l}1200 \sim 38400 \mathrm{bps} \text { (determine } \\
\text { before leaving factory) }\end{array}$ & $\begin{array}{l}\text { Operating } \\
\text { humidity }\end{array}$ & $\begin{array}{l}10 \% \sim 90 \% \text { relative humidity; no } \\
\text { condensation }\end{array}$ \\
\hline
\end{tabular}

\section{The design of data signal concentrator}

To achieve the function of data signal centralized processing of the electronic protection device, this study designed a data concentrator $[13,14]$ to receive the data of the sensors, wireless data transmission module and reference handles, analyzed the data, and transmitted them to the upper computer. The data concentrator designed in this study mainly adopted single chip as the hardware core, and moreover software functions such as serial port communication and network communication were designed. The hardware structure of the single chip microcomputer based data concentrator is as follows. The single chip based data concentrator used is shown in figure 3.

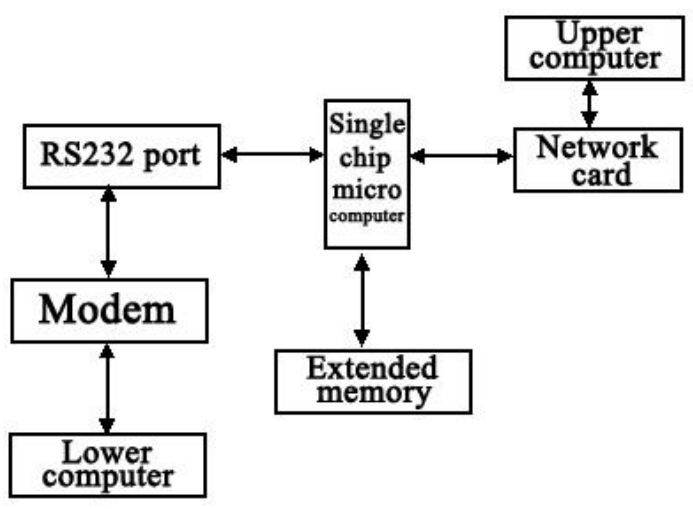

Figure 6: The hardware structure of the single chip microcomputer based data concentrator 


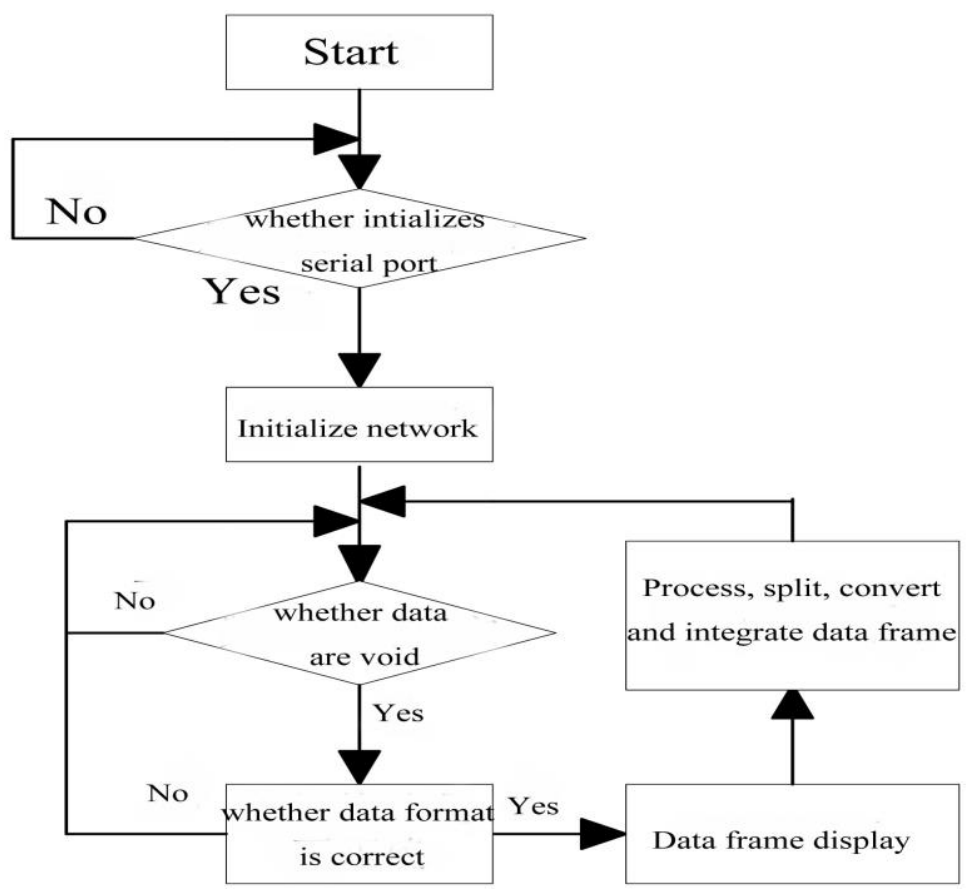

Figure 7: Design of main program of software

\section{Design of main program of software in the data concentrator}

Firstly, the data concentrator was initialized. If the initialization of the serial port failed and there was data frame, format examination was performed. If the format was correct, then it was sent for processing; otherwise, it was abandoned. One of the main functions of the data concentrator was protocol analysis including grammar analysis, framing and composite frame.

The detailed flow is shown in figure 7.

\section{The experimental simulation and analysis}

\subsection{Sensor simulation}

To verify the feasibility of the designed optical fiber sensor, this experiment took a lasing diode with fiber pigtail output as the light source and SMF-28e (diameter of optical fiber core $1=4.6 \mu \mathrm{m}$; numerical aperture $\mathrm{NL}=0.14$; fiber core refractive index $\mathrm{n}=$
1.4676) as the sensitive optical fiber. $\Lambda_{c}$ (the best microbend cycle) was $0.214 \mathrm{~mm}$ after the calculation using the formula $\Lambda_{c}=\frac{\sqrt{2} \ln \pi}{N L}$. To ensure the smooth proceeding of the experiment, $6.42 \mathrm{~mm}$ which was 3 times that of $\Lambda_{c}$ was taken as the microbend cycle and the microbend number of the microbend modulator was set as 3; under such conditions, both the sensitivity and repeatability of the sensor were good. In addition, an optical fiber microbend sensing system structure device was used for testing. Impact force designator was used to simulate the hitting strength of Sanda athletes. A microbend modulator was set below the designator. Different output voltage values were obtained based on the property that the microbend degree of optical fibers are different under different impact force received by microbend modulator. Table 1 demonstrates the relationship between the output voltage and the hitting strength.

Table 2: The relationship between output voltage and hitting strength

\begin{tabular}{|l|c|c|c|c|c|c|c|c|}
\hline $\begin{array}{l}\text { Hitting } \\
\text { strength/N }\end{array}$ & 20 & 40 & 60 & 80 & 100 & 120 & 140 & 160 \\
\hline $\begin{array}{l}\text { Output } \\
\text { voltage/V }\end{array}$ & 9.0 & 8.1 & 7.2 & 5.9 & 5.0 & 4.3 & 3.1 & 1.8 \\
\hline
\end{tabular}

It was known from table 2 that, the relationship between the output voltage and the hitting strength approximated to linear function within certain range [15], indicating the optical fiber microbend sensor had relatively good linearity and repeatability within certain range and it could determine the hitting strength of athletes based on the output voltage value and implement the function of automatic scoring in Sanda competition. 


\subsection{Circuit simulation}

After the design of the charge amplifier circuit, general functional tests were made. Firstly, $3.3 \mathrm{~V}$ power source was supplied to the circuit; then the output end after filtering was monitored using an oscilloscope [16]; the sensing face of the sensor was pressed. The following testing results were obtained
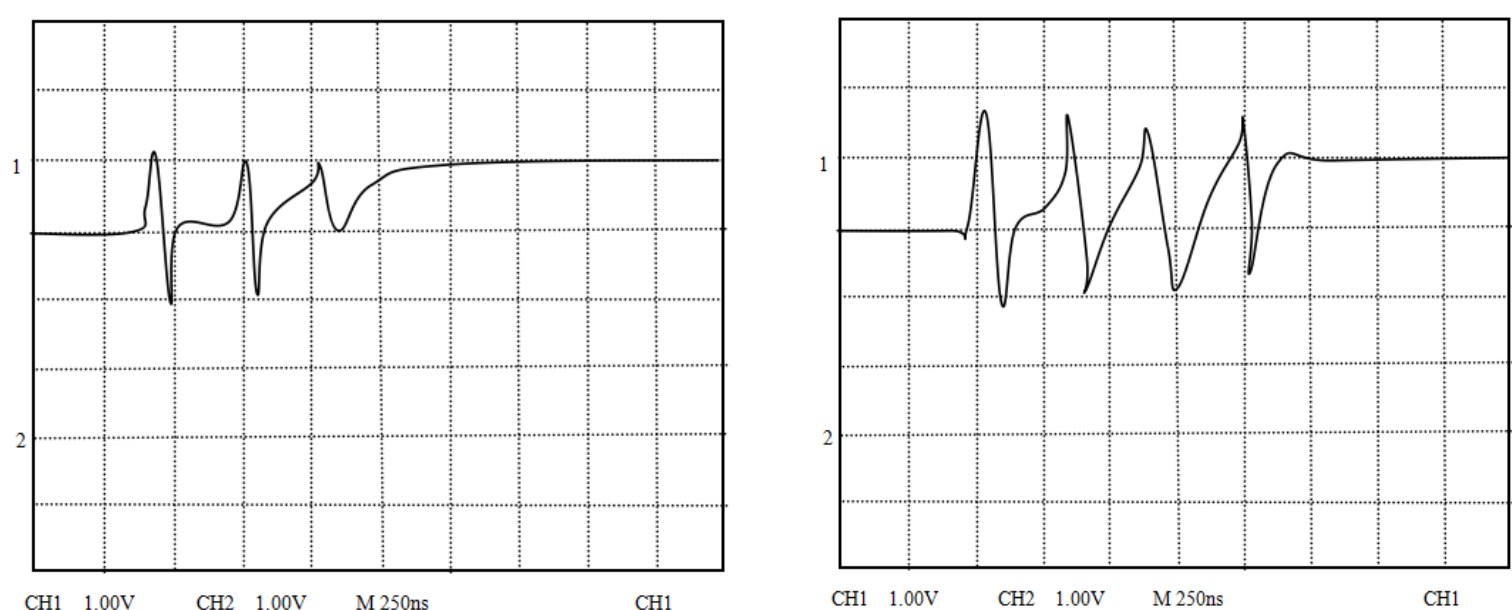

Figure 8,9: The effect pictures for the oscilloscope of the charge amplifier

It could be known from the figures that, there was an obvious waveform in every time of pressing and different degrees of pressing could result in different amplitudes of waveforms, indicating the circuit was feasible. The application of the circuit could accurately detect the impact force received by the electronic protection device within certain range, thus to achieve corresponding hardware functions.

\section{Overall power consumption of the system}

In the actual Sanda competitions, two athletes also test and circle round for a long period rather than keep attacking constantly.
If a single chip microcomputer operated in a high speed in the period, there would be a large load and electric energy loss. Hence the system was unnecessary to operate in that period and kept in a stand-by state.

When the system was in a stand-by state, low power consumption mode was set, the other unnecessary programs were closed to reduce the consumption of electric quantity, and it was compared to the operation results of the system which was not inserted with low power consumption executive code (Table 3).

Table 3: Testing of power consumption of the two systems

\begin{tabular}{|c|l|l|}
\hline Testing events & \multicolumn{1}{|c|}{$\begin{array}{c}\text { Low power energy consumption } \\
\text { system }\end{array}$} & \multicolumn{1}{c|}{ Ordinary system } \\
\hline $\begin{array}{c}\text { Testing } \\
\text { duration }\end{array}$ & $\begin{array}{l}\text { 20 hours; power source and voltage } \\
\text { kept stable }\end{array}$ & $\begin{array}{l}\text { 5 hours; power source and voltage } \\
\text { rapidly degrade and battery is low }\end{array}$ \\
\hline Testing effect & Some results omit after stand by & $\begin{array}{l}\text { Accurate test; operate normally after } \\
\text { restart }\end{array}$ \\
\hline $\begin{array}{c}\text { The condition } \\
\text { of system }\end{array}$ & $\begin{array}{l}\text { Good, no obviously abnormal } \\
\text { situation }\end{array}$ & $\begin{array}{l}\text { Serious burning hot when some } \\
\text { modules operated }\end{array}$ \\
\hline
\end{tabular}

It could be noted in table 1 that, the power consumption of the system equipped with low power consumption program was less than that of the ordinary system and the operation effects of the two systems had no significant difference. It indicated that, the insertion of the low power consumption program into the system was feasible and benefit to the overall stable operation of the Sanda electronic protection device.

\section{Conclusion}

The development of Sanda electronic protection devices can promote the intelligentization and highspeed orientation of traditional Sanda competition, make Sanda competition more professional, fair and pleasing, and lay a certain basis for the promotion and popularization of Sanda and the transmission of Chinese Wushu in the world. 
Thus this study put forward a research approach for Sanda electronic protection devices and implemented its hardware functions through designing the equipment such as optical fiber microbend sensor, system circuit and referee handle. He W. et al. [17] designed and studied electric protection devices for fighting. The force measurement was designed using e-Touch piezoelectric film sensor, the circuit was regulated, and finally system simulation was performed. To achieve the signal control of the electronic protection device, the wireless data module and data concentrator were designed for the acquisition, processing and transmission of data signal during Sanda competition. In addition, an experimental simulation was made to test its feasibility. The testing results demonstrated that, the design was feasible and quite applicable to Sanda competition. Though the development and design of Sanda electronic protection device has been completed in this study, the design is not so complete and remains to be improved in the future due to the limited time and the small number of researches concerning Sanda electronic protection devices. All the functions of Sanda electronic protection devices are expected to be implemented to spread Sanda over the world.

\section{References}

[1] Baddour, L. M., Epstein, A. E., Erickson, C. C., et al, "Update on cardiovascular implantable electronic device infections and their management: a scientific statement from the American Heart Association" Circulation, 2010, 121(3):458-77.

[2] Yamagata, K., Oda, N., Kaisaki, P. J., et al, "Image sensor and method for reading out pixels of the image sensor" Nature, 2012, 384(6608):458460.

[3] Gheorghe, G., Simona, I., Veronica, Despa., Adriana Cirstoiu, C., "Researchs regarding intelligent sensors and actuators of high precision used in precision mechanics, mechatronics and robotics domain" Romanian Review Precision Mechanics, Optics and Mechatronics, 2010, 38:201-204.

[4] Jing, J. and Qin, Y., "Research of Application of Free Combat Kicks Technical Defense" Hubei Sports Science, 2013, 57(1):119-133.

[5] Wang, N., "Research on Design of Free Combat Attack and Defense Action Based on Wireless Sensor Motion Recognition" Applied Mechanics \& Materials, 2014, 602-605:2075-2078.
[6] Kieran, S., Dunne, J. J. and Fenton, J., "The effect of head protection on the hearing of rugby players" British Journal of Sports Medicine, 2008, 42(9):779-80.

[7] Okabe, Y., Medzhitov, R., "Tissue-Specific Signals Control Reversible Program of Localization and Functional Polarization of Macrophages" Cell, 2014, 157(4):832-844.

[8] Abdulhai, B., Pringle, R. and Karakoulas, G. J., "Reinforcement Learning for the True Adaptive Traffic Signal Control” Journal of Transportation Engineering, 2014, 129:278-285.

[9] Liu, M., Yin, X., Ulin-Avila, E., et al., "A graphenebased broadband optical modulator" Nature, 2011, 474(7349):64-7.

[10] Wei, T. Y., Chen, C. H., Chien, H. C., et al., "A CostEffective Supercapacitor Material of Ultrahigh Specific Capacitances: Spinel Nickel Cobaltite Aerogels from an Epoxide-Driven Sol-Gel Process" Advanced Materials, 2010, 22(3):34751.

[11] Wang, J., Yang, J. Y., Fazal, I. M., et al., "Terabit free-space data transmission employing orbital angular momentum multiplexing" Nature Photonics, 2012, 6(7):488-496.

[12] Zorzi, M., Rao, R. R. and Milstein, L. B., "On the accuracy of a first-order Markov model for data transmission on fading channels" // IEEE International Conference on Universal Personal Communications. 2013:211 - 215.

[13] Adamiak, M. G., Kanabar, M., Rodriquez, J., et al., "Design and implementation of a synchrophasor data concentrator" // Innovative Smart Grid Technologies - Middle East. IEEE, 2011:299-310.

[14] Kanabar, M., Adamiak, M. G. and Rodrigues, J., "Optimizing Wide Area Measurement System architectures with advancements in Phasor Data Concentrators (PDCs)" // Power and Energy Society General Meeting (PES), 2013 IEEE. IEEE, 2013:1-5.

[15] Yang, S. S., "Linear Functions of Concomitants of Order Statistics with Application to Nonparametric Estimation of a Regression Function" Journal of the American Statistical Association, 2012, 76(375):658-662.

[16] Yang, Y., Zhang, C. and Fathy, A. E., "Development and Implementation of UltraWideband See-Through-Wall Imaging System Based on Sampling Oscilloscope" // International Symposium on Photoelectronic Detection and Imaging. International Society for Optics and Photonics, 2011:1190-1193.

[17] He, W., Lei, T., Zhai S. H., "Research of the Fighting Electronic Gear Force Transducer and Its Control Circuit" Journal of Transduction Technology, 2014(10):1382-1386. 